\title{
EGG WEIGHTS, EGG COMPONENT WEIGHTS, AND LAYING GAPS IN GREAT TITS (PARUS MAJOR) IN RELATION TO AMBIENT TEMPERATURE
}

\author{
C. M. Lessells, ${ }^{1,3}$ N. J. Dingemanse, ${ }^{1}$ AND C. Both ${ }^{1,2}$ \\ ${ }^{1}$ Netherlands Institute of Ecology, Boterhoeksestraat 48, P.O. Box 40, 6666 ZG Heteren, The Netherlands; and \\ ${ }^{2}$ Zoological Laboratory, University of Groningen, P.O. Box 14, 9750 AA Haren, The Netherlands
}

\begin{abstract}
We collected 328 freshly laid Great Tit (Parus major) eggs from 38 clutches in 1999 to determine the relationship of whole egg weight, wet yolk weight, wet albumen weight, dry shell weight, and the occurrence of laying gaps with mean ambient temperature in the three days preceding laying, while controlling for laying date and position in the laying sequence. We also reanalyzed existing data on whole egg weight in 1978 and 1979 in relation to temperature, controlling for the same other variables. Egg weight was correlated with temperature in 1978 and 1979, but not in 1999. None of the egg components was related to temperature preceding laying, apart from a nonsignificant tendency for albumen weights to be lower at higher temperature. Egg weight increased with laying date in 1978 and 1979 after controlling for other variables. In 1999, albumen and shell weight increased seasonally, but shell weight only did so to the extent expected on the basis of the seasonal increase in whole egg weight. Yolk weight did not increase significantly seasonally, but neither did yolk weight relative to whole egg weight decrease significantly. Whole egg weight and the weights of all components varied between clutches. Most weights also varied through the laying sequence. The probability of a laying gap occurring varied between clutches, and increased with position in the laying sequence and decreased with temperature and laying date. Eggs preceding laying gaps were lighter and contained less albumen but had higher shell weights than other eggs. Eggs following laying gaps also had heavier shells relative to the size of the egg than other eggs. Received 19 May 2000, accepted 31 August 2002.
\end{abstract}

RESUMEN.-Colectamos 328 huevos recién puestos de 38 nidadas de Parus major en 1999 para determinar la relación del peso total del huevo, el peso fresco de la yema, el peso fresco del albúmen, el peso seco del cascarón y la ocurrencia de interrupciones en la postura, con la temperatura media del ambiente en los tres días previos a la postura (controlando por la fecha de postura y la posición en la secuencia de postura). También reanalizamos datos existentes sobre el peso total del huevo en 1978 y 1979 con relación a la temperatura, controlando por las mismas variables adicionales. El peso del huevo se correlacionó con la temperatura en 1978 y 1979, pero no en 1999. Ninguno de los componentes del huevo estuvo relacionado con la temperatura previa a la postura, pero hubo una tendencia no significativa en la que el peso del albúmen fue menor a mayores temperaturas. Tras controlar por otras variables, el peso del huevo aumentó con la fecha de postura en 1978 y 1979. El peso de albúmen y del cascarón aumentaron estacionalmente en 1999, pero el peso del cascarón sólo lo hizo hasta el nivel esperado con base en el incremento estacional en el peso total del huevo. El peso de la yema no aumentó estacionalmente, pero su peso relativo al peso total del huevo no disminuyó significativamente. El peso total del huevo y sus distintos componentes variaron entre nidadas. La mayoría de los pesos también variaron a través de la secuencia de postura. La probabilidad de que ocurriera una interrupción en la postura varió entre nidadas, aumentó con la posición en la secuencia de postura y disminuyó con la temperatura y la fecha de postura. Los huevos que precedieron interrupciones fueron más livianos y tuvieron menos albúmen, pero presentaron cascarones más pesados que otros huevos. Los huevos que siguieron a las interrupciones también tuvieron cascarones más pesados (con relación al tamaño del huevo) que otros huevos.

IN MANY BIRD SPECIES, the earliest hatching broods often give rise to the fittest young,

\footnotetext{
${ }^{3}$ Present address: NIOO, Boterhoeksestraat 48, 6666 ZG Heteren, The Netherlands. E-mail: k.lessells@nioo.knaw.nl
}

therefore there is selection for earlier breeding (Perrins 1965, 1991; van Noordwijk et al. 1995). That observation has stimulated the idea that females are prevented from breeding earlier because they have insufficient resources to produce a clutch of eggs, and has focused attention 
on the possibility of energetic constraints during the laying period (Perrins 1970, 1996). Two lines of evidence have been adduced in support of this notion: first, supplementary feeding experiments have investigated whether increased food availability advances the start of laying or increases clutch or egg size (Martin 1987, Arcese and Smith 1988, Boutin 1990, Meijer and Drent 1999). Second, similar relationships have been sought between breeding performance and ambient temperature. An increase in ambient temperature may improve the energetic status of laying females in one or more of the following ways: higher temperatures may reduce the energetic cost of thermoregulation of the female (Nager and van Noordwijk 1992, Stevenson and Bryant 2000), or increase the availability of food for insectivorous species, either by accelerating the development of the insect prey (Jones 1973 in Ojanen et al. 1981), or by increasing foraging efficiency on existing prey (Avery and Krebs 1984).

Both observations and experiments have previously revealed an effect of ambient temperature on egg size and the occurrence of laying gaps. On the basis of correlational data, temperature in the period preceding laying has been shown to have a positive effect on individual egg weights in Goldcrests (Regulus regulus; Haftorn 1986), Pied Flycatchers (Ficedula hypoleuca; Ojanen et al. 1981, Järvinen and Ylimaunu 1986), Great Tits (Parus major; Ojanen et al. 1981, van Noordwijk 1984, Perrins 1996), Common Grackles (Quiscalus quiscula; Howe 1978) and European Starlings (Sturnus vulgaris; Ojanen et al. 1981) and on the mean egg weight of clutches in Pied Flycatchers (Järvinen 1991), Common Redstarts (Phoenicurus phonenicurus; Järvinen 1991), Eurasian Blackbirds (Turdus merula; Magrarth 1992), and Great Tits (Nager and Zandt 1994, Järvinen and Pryl 1989, Nager and van Noordwijk 1992, Perrins 1996). However, many of the above analyses do not control for other variables, including laying date, to which both egg weight and temperature may be correlated (e.g. Magrath 1992). Such analyses are necessary because females may vary egg size in relation to laying date per se in order to anticipate seasonal changes in costs and benefits to nestlings of hatching from large eggs (Birkhead and Nettleship 1982, Magrath 1992).
In addition to the above observational studies, two experimental studies have been carried out manipulating night temperature during the prelaying and laying period: female Great Tits that were experimentally heated while roosting in the nest box overnight laid larger eggs than those that were experimentally cooled (Nager and van Noordwijk 1992), but female Blue Tits (Parus caeruleus) that were experimentally heated in a similar way did not lay larger eggs and were instead less likely to have laying gaps than control females (Yom-Tov and Wright 1993; laying gaps also occurred four to five days after low minimum temperatures in control females). However, although such experimental studies have the potential to unequivocally identify temperature as the causal factor affecting egg weight, no attempt was made in the above studies to investigate whether all egg components were equally affected by the experiment. Among the observational studies cited above, only Ojanen (1983a) investigated the relationship between egg components and temperature, and showed that in Great Tits, and to a lesser extent Pied Flycatchers, the energetic content of the yolk, the albumen and shell combined, and the whole egg increased with ambient temperature. In general, larger eggs within a species also contain more of each egg or chemical component (Williams 1994), but whether the relationship between each component and whole egg size is independent of the source of the egg size variation is to a large extent an open question. For example, in several species eggs vary in composition through the laying sequence over and above the variation expected on the basis of changes in egg size (e.g. Ojanen 1983a, Kennamer et al. 1997).

The aim of this study therefore was to investigate egg weight variation within clutches and the occurrence of laying gaps in Great Tits in relation to ambient temperature. The analyses are based on observational data, but we have attempted to answer the above two criticisms: the analyses of newly collected data control for other variables, including laying date, and have been carried out on wet yolk, wet albumen, and dry shell weight as well as whole egg weight. We also repeat the analysis on whole egg weight carried out by van Noordwijk (1984), but controlling for the same other variables as in the analyses of newly collected data. 


\section{Methods}

1999 data: Whole egg, yolk, albumen, and shell weights.-Eggs were collected from a nest-box population of Great Tits at Westerheide, a mixed woodland in the Veluwe, The Netherlands. Nest boxes were checked at least twice weekly from the beginning of April 1999, and daily after the box contained more than half a nest. Any eggs laid after the previous nest check were replaced with plastic eggs. There was no indication that those dummy eggs were not treated as normal eggs. Daily nest checks were continued until at least two days after the previous egg was laid, and only eggs from clutches where incubation was begun were included in the analyses.

Eggs were removed to the laboratory. They were weighed (all weights to the nearest milligram), broken open, and the yolk separated from the remainder of the egg. Excess albumen was removed from the yolk by rolling it on a piece of paper, and the yolk weighed. The shell (including the shell membrane) was washed, dried to constant weight at $60^{\circ} \mathrm{C}$, and weighed. Albumen weight was obtained by subtracting the wet yolk and dry shell weights from the total weight, and therefore includes the water content of the shell. That was done to reduce variability introduced by varying amounts of albumen adhering to the inside of the shell. Based on wet and dry egg components for Great Tit eggs separated without boiling (i.e. with albumen adhering to the shell; Ojanen 1983b), wet albumen weight has been overestimated by a maximum of $7 \%$. Based on the proportional water content of shells of eggs of two larger species separated after boiling (31.5\%; Ankney and Johnson 1985, Muma and Ankney 1987), albumen weight has been overestimated here by $\sim 4 \%$. Dry yolk and albumen weights were not obtained because the wet yolk was required for another analysis. Eggs were generally weighed before 1700 hours, and $94 \%$ of the eggs were weighed on the day of laying. The analysis was carried out on those clutches because they were being removed in any case as part of a manipulation experiment.

Weather data were obtained from the Royal Dutch Meteorological Institute's (KNMI) site at De Bilt, 50 $\mathrm{km}$ west of the study area. The temperature variable used in the analyses was the mean temperature for the three days preceding laying of each egg. That variable was chosen because it is the variable used in other analyses of Great Tits (van Noordwijk 1984, Nager and Zandt 1994, Nager and van Noordwijk 1992), and because temperature variables tend to be highly correlated between successive days so that choosing a different time window would not have substantially altered the results of the analysis.

1978 and 1979 data: Whole egg weights only.-Van Noordwijk (1984) investigated the weights of individual eggs from the Hoge Veluwe, a study site $\sim 2$ $\mathrm{km}$ northeast of Westerheide, in relation to temperature. To repeat his analyses controlling for other variables, we reconstituted a data set from the longterm Great Tit data base of the Netherlands Institute of Ecology, because the original data used by van Noordwijk were no longer available as a discrete data set. Eggs were included in the analysis if (a) they came from first clutches that were subsequently incubated, (b) the nest had been checked on the day before the egg was laid (except for first eggs, where previous visits appear usually not to have been documented in the currently available records), (c) no other egg from that nest was weighed on the same day, and (d) at least three eggs from the clutch met criteria (b) and (c). Visual comparison of these data with those presented in figure 1 of van Noordwijk (1984) suggests that the data set that we analyzed is similar, but not identical, to that analyzed by van Noordwijk. In addition, we used weather data from De Bilt, rather than from Deelen (the weather station used by A. van Noordwijk; A. J. van Noordwijk pers. comm.). Mean daily temperatures were highly correlated between these two weather stations in April $1978\left(r^{2}=0.95\right)$ and $1979\left(r^{2}=0.99\right)$. Because the selection criteria resulted in incomplete data for many clutches in 1978 and 1979, no attempt was made to analyze laying gaps in those clutches.

Statistical analysis. - The main purpose of the analysis presented here was to investigate how individual egg weights vary with temperature, laying date, laying order, and between clutches. However, those explanatory variables are highly correlated: for the data sets analyzed, laying date and temperature vary significantly between clutches in all three years (oneway ANOVA: all $P<0.001$, except for temperature in 1978 where $P=0.015)$, and temperature, laying date and laying order are significantly $(P<0.001)$ intercorrelated in all years except for temperature with laying date and laying order in 1978. A series of general linear models was therefore built (using SAS and GLIM) in an attempt to disentangle the effects of those variables, in each case assessing the significance of the explanatory variable when it was entered last into the model. (a) Initially, we included only the explanatory variable of interest in the model. This analysis included both within and between clutch variation in egg weight and indicated whether the explanatory variable might have an influence on the weight being analyzed. (b) Next, we included clutch as a factor in the model to investigate whether there was a relationship with the explanatory variable within clutches. An explanatory variable might become significant (compared with analysis [a]) if an effect was previously swamped by large variation between clutches, or lose significance if the relationship occurred only between and not within clutches. (c) Third, we included all other explanatory variables in the model, whether they were significant or not. Because we tested significance of each variable when it 
TABLE 1. Summary of the relationships between egg, yolk, albumen or shell weight and laying sequence, laying date, and temperature preceding laying. Results are from general linear models including the explanatory variable listed (a) alone, (b) after controlling for clutch, (c) after controlling for clutch and the other explanatory variables listed in the table, and (d) after controlling for other significant variables. The symbols - and + indicate the sign of the regression coefficient. For egg number, the first sign indicates the sign of the linear regression coefficient, and the second the sign of the quadratic regression coefficient. (Thus the first sign indicates the initial slope, and the second the final slope; e.g. -+ indicates a $U$-shaped curve.) Where the turning point is outside the observed range of egg numbers, the sign indicating the slope that does not occur over the observed range is enclosed in parentheses.

\begin{tabular}{|c|c|c|c|c|c|c|c|c|c|c|c|}
\hline \multirow{4}{*}{$\begin{array}{c}\text { Other variables in the model } \\
\text { Tested variable }\end{array}$} & & \multicolumn{7}{|c|}{ (a) Variable alone in model } & \multicolumn{3}{|c|}{$\begin{array}{l}\text { (b) Controlling } \\
\text { for clutch }\end{array}$} \\
\hline & & \multicolumn{7}{|c|}{ None } & \multicolumn{3}{|c|}{ Clutch } \\
\hline & & \multicolumn{3}{|c|}{ Egg number } & \multicolumn{2}{|c|}{ Date } & \multicolumn{2}{|c|}{ Temperature } & \multicolumn{3}{|c|}{ Egg number } \\
\hline & $n$ & $\begin{array}{l}\text { Lin- } \\
\text { ear }\end{array}$ & $\begin{array}{l}\text { Qua- } \\
\text { drat- } \\
\text { ic }\end{array}$ & $P$ & $\begin{array}{l}\text { Lin- } \\
\text { ear }\end{array}$ & $P$ & $\begin{array}{l}\text { Lin- } \\
\text { ear }\end{array}$ & $P$ & $\begin{array}{l}\text { Lin- } \\
\text { ear }\end{array}$ & $\begin{array}{l}\text { Qua- } \\
\text { dratic }\end{array}$ & $P$ \\
\hline 1978: Egg weight & 233 & & & & & & + & 0.055 & + & + & $* * *$ \\
\hline 1979: Egg weight & 201 & & & & + & 0.083 & + & $* *$ & & & \\
\hline 1999: Whole egg & 305 & & & & + & $* * *$ & + & $* * *$ & - & + & $*$ \\
\hline Yolk & 303 & - & + & $* * *$ & + & * & & & - & + & $* * *$ \\
\hline Yolk controlling for egg weight & 302 & - & + & $* * *$ & - & $* *$ & - & * & - & + & $* * *$ \\
\hline Albumen & 298 & & & & + & $* * *$ & + & $* * *$ & - & + & $* * *$ \\
\hline Shell & 301 & + & + & $* * *$ & + & $* * *$ & + & $* * *$ & + & $(-)$ & $* * *$ \\
\hline Shell controlling for egg weight & 299 & + & + & $* * *$ & + & $* * *$ & + & $* *$ & + & - & $* * *$ \\
\hline
\end{tabular}

${ }^{*} P<0.05 ;{ }^{* *} P<0.01 ;{ }^{* *} P<0.001$; exact $P$ values are given when $0.10>P>0.05$. The significance of other variables was not altered by the inclusion of temperature in the best model for albumen weight.

was entered last into the model, this analysis is conservative. Each variable is only allocated its effect over and above any effects of other tested variables. As a result, when two explanatory variables-both highly correlated with the response variable-are themselves highly correlated, it is possible that neither of them is significant. (d) Last, for completeness, we constructed the "best" model, containing only those explanatory variables that were significant when entered last into the final model (see Table 1). The main difference from the previous models is that when there are two highly correlated explanatory variables, the one explaining more of the variance (but not necessarily significantly more) is included in the model. Clutch was always significant when entered alone, or with any other listed combination of explanatory variables $(P<0.001)$. Significance tests were carried out with the tested explanatory variable entered last into the model. Egg number was tested and controlled for by entering linear and quadratic terms simultaneously into the model, except in the best model, where the quadratic term was only entered if it significantly increased the variance explained. If the linear and quadratic terms were nonsignificant when tested together, the linear term was always also nonsignificant when tested alone. A cubic term in egg number was never significant. The significance of clutch and egg number were tested using the error MS as the denominator MS. Because eggs laid on the same day had the same values of date and temperature variables, those variables were tested using the residual MS between days (as a factor) as the denominator MS. We included only linear terms for date and temperature, because in 1979 and 1999 temperature approximated a quadratic function of date (see Fig. 1). In general, we did not include interactions because we were most interested in main effects. That also limited the number of terms that were tested in the analyses and hence reduced the probability of Type 1 statistical errors. Other details of the analyses are given in table and figure captions.

\section{Results}

In 1999, data were collected from 328 eggs from 38 clutches that were subsequently incubated by Great Tits, constituting all but 6 of the first Great Tit clutches incubated in the study area. The exact laying date was known for $93.9 \%$ of those eggs, and laying order was known for $96.6 \%$. Two eggs $(11.6 \times 9.4 \mathrm{~mm}$, $0.53 \mathrm{~g} ; 23.8 \times 12.3 \mathrm{~mm}, 1.80 \mathrm{~g}$ ) were outliers to the length, breadth, or weight distributions, and hence excluded from the analyses (Dixon's test for outliers [Sokal and Rohlf 1995]; $P \ll$ 0.001). Other eggs have been excluded from 
TABLE 1. Extended.

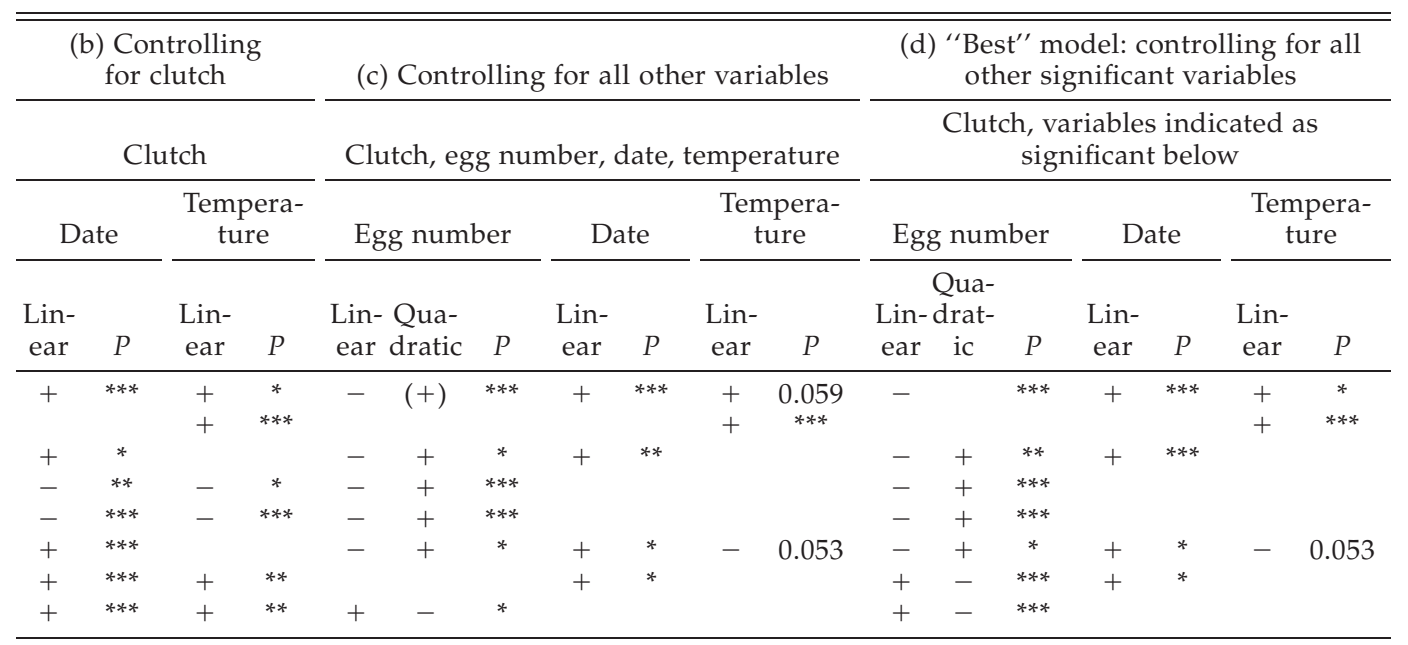

analyses when relevant data were missing. The first eggs were found on 8 April (estimated onset of laying 7 April), and the last egg was laid on 5 May.

Weights of individual eggs with known laying date from the Hoge Veluwe were extracted from the database for 235 eggs from 29 clutches in 1978, and 201 eggs in 37 clutches in 1979. Two eggs laid in 1978 were excluded because they were outliers to the length distribution $(20.6 \times 13.6 \mathrm{~mm}, 1.93 \mathrm{~g}, P<0.05 ; 21.9 \times 12.1$ $\mathrm{mm}, 1.78 \mathrm{~g}, P<0.001)$.

Egg components and allometric relationships.In 1999, mean egg weight was $1.60 \pm 0.13 \mathrm{~g}$ $(\mathrm{SD}, n=305)$, wet yolk weight $0.31 \pm 0.04 \mathrm{~g}(n$ $=303)$, wet albumen weight $1.20 \pm 0.11 \mathrm{~g}(n=$ 298), and dry shell weight $95.4 \pm 9.0 \mathrm{mg}(n=$ 301). Based on a water content of shell of $31.5 \%$ (Ankney and Johnson 1985, Muma and Ankney 1987), wet yolk, wet albumen, and wet shell constituted approximately 19, 72, and 9\%, respectively, of the fresh egg weight. The exponent, $b$, of the allometric relationship $\left(y=a \cdot x^{b}\right)$ between yolk or shell weight and whole egg weight was obtained from the slope of the regression of $\log$ (yolk weight) or $\log$ (shell weight) on $\log ($ whole egg weight). The value of $b$ indicates whether the weight of the egg component increases in direct proportion to the whole egg weight. When it does so, $b$ has the value 1. If the component increases less than in proportion (for instance, if the yolk less than doubles in weight when the whole egg weight doubles), $b$ has a value $<1$, and when the component increases more than in proportion, $b$ has a value $>1$. Between-clutch relationships were obtained using mean weights per clutch, and within-clutch relationships from ANCOVA with clutch fitted as a factor. Yolk weight increased in proportion to whole egg weight within clutches $(b=0.980 \pm 0.071$ [SE]; $t$ for difference from $1=0.28$, NS), but less than in proportion to whole egg weight between clutches $(b=0.603 \pm 0.180, t=2.76, P<0.001)$. The reverse pattern occurred for shell weight, which increased in proportion with egg weight between clutches $(b=0.836 \pm 0.112, t=1.46$, NS), but less than in proportion within clutches $(b=0.608 \pm 0.093, t=4.21, P<0.001$; comparison between yolk and shell for difference of within and between slopes, $t=2.50, P<0.05)$.

Whole egg weights in relation to clutch, laying order, laying date, and temperature.-Daily mean egg weights and temperature in relation to date 
A Hoge Veluwe 1978

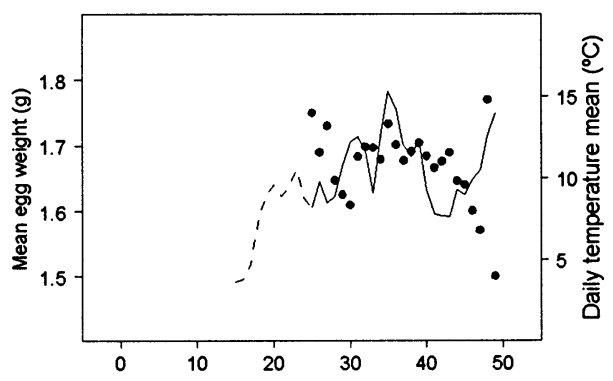

B Hoge Veluwe 1979

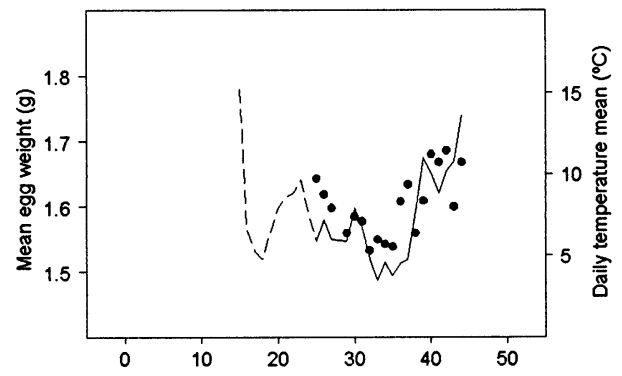

C Westerheide 1999

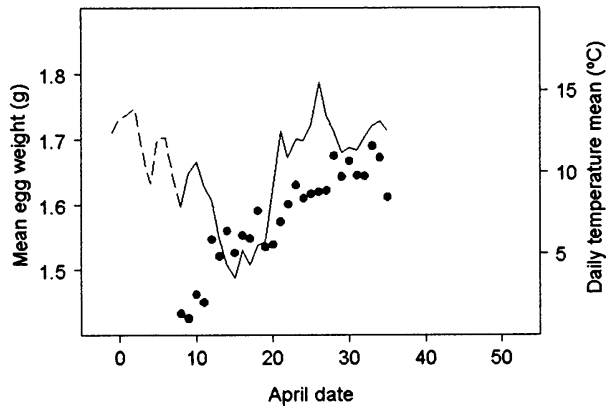

FIG. 1. Seasonal variation in Great Tit egg weight and temperature at (A) the Hoge Veluwe in 1978, (B) the Hoge Veluwe in 1979, and (C) Westerheide in 1999. Points represent daily mean egg weights. Lines join the daily mean temperature (solid during the period when analyzed eggs were laid; dashed line during the preceding 10 days).

are shown in Figure 1. Variation in the daily mean egg weights includes both within and between clutch variation. In 1978, temperatures during the laying period were comparatively high and uniform, with daily mean temperature never dropping below $7.6^{\circ} \mathrm{C}$. In 1979 and 1999, temperatures were coldest in the middle of the laying period, the daily mean dropping to $3.5^{\circ} \mathrm{C}$ in both 1979 and 1999 . That pattern of temperature change increases the possibility of detecting relationships of egg weight to laying date or temperature independently. Laying occurred considerably earlier in 1999 than in 1978 or 1979: mean laying date of eggs whose weights were analyzed were 6 May, 4 May, and 23 April in 1978, 1979, and 1999, respectively.

Whole egg weight varied significantly between clutches in all years irrespective of the other variables included in the model (all $P<$ 0.001). The results of the general linear modeling for other explanatory variables are given in Table 1. In 1999, egg weight increased with both laying date and temperature when no other variables were included in the model. However, in the analyses controlling for clutch and other variables, the relationship with temperature disappeared, so there is no unequivocal evidence for an effect of temperature on egg weight in that year. (That was also true when egg weight [both linear and quadratic terms], but not date, was controlled for.) Both laying order and laying date remained significant when other variables were controlled for, implying that those variables had a significant effect on egg weight. Egg weight increased with laying date (Fig. 1C), and initially decreased and then increased through the laying sequence. Analyses controlling for clutch consider only withinclutch variation for other explanatory variables in the model. Between-clutch variation was investigated by analyzing mean egg weights. Those increased with both laying date (of the first egg of the clutch; $F=5.15, \mathrm{df}=1$ and 36 , $P=0.029)$ and temperature $(F=6.85, \mathrm{df}=1$ and $36, P=0.013$ ) when those explanatory variables were considered alone, but neither laying date or temperature explained a significant additional amount of variance over and above the other variable (both $P>0.2$ ). Thus, effects of laying date and temperature on the average whole egg weight of clutches cannot be separated statistically.

In contrast to 1999, in both 1978 and 1979 individual egg weights increased with temperature whichever other variables were controlled for. (Temperature was marginally nonsignificant $[P=0.059]$ in 1978 when a nonsignificant quadratic egg number term was included in the model, but significant $[P=0.013]$ when this term was omitted.) The regression coefficients in the best models imply that egg weight increased within clutches by $5.1 \mathrm{mg}$ for each $1^{\circ} \mathrm{C}$ rise in temperature in 1978, and $18.3 \mathrm{mg}$ in 
1979. In 1978, but not 1979, there was also evidence for a significant increase in egg weight with laying date, and decrease with position in laying sequence. Van Noordwijk (1984) suggested that there was a threshold temperature of $10^{\circ} \mathrm{C}$ above which egg size did not increase with increasing temperature. We tested for the existence of nonlinearity in the relationship between egg size and temperature by fitting a quadratic term in temperature. The quadratic term was not significant in $1978(P>0.10)$, $1979(P>0.75)$, or both years combined $(P>$ 0.75). When the data for 1978 and 1979 are analyzed together (without temperature ${ }^{2}$ in the model), the main effects are all significant (model containing all variables: egg number [linear and quadratic terms], $P<0.001$; laying date, $P<0.05$; temperature, $P<0.001$ ). However, the first-order interactions between year and egg number, laying date and temperature are all significant (tested over the residual MS between days; see text; year $\times$ egg number + year $\times$ egg number ${ }^{2}, P<0.01$; year $\times$ laying date, $P<0.01$; year $\times$ temperature, $P<0.01$ ). Thus, the slope of the relationship between egg weight and those variables differs between 1978 and 1979. Similarly, when the data for all three years are analyzed together, the main effects are all significant (model containing all variables: egg number [linear and quadratic terms], laying date and temperature, all $P<$ 0.001), but the interaction between site (i.e. 1978 and 1979 vs. 1999) and temperature is also significant (tested over the residual MS between days; $P<0.001$ ). Thus, the relationship between egg weight and temperature differs between the two earlier years (1978 and 1979) and 1999.

Yolk, albumen, and shell weights in relation to clutch, laying order, laying date, and temperature.In addition to the analyses of yolk, albumen, and shell weight, analyses were also carried out on yolk and shell weight controlling for the weight of the whole egg (by including egg weight as an explanatory variable in all the models). Yolk, albumen, and shell weight (and yolk and shell weight controlled for whole egg weight) all varied significantly between clutches irrespective of the other explanatory variables included in the model (all $P<0.001$ ). The results of the general linear modeling for other explanatory variables are given in Table 1 . Both albumen and shell weight increase with tem- perature, when that is the only explanatory variable in the model, whereas yolk controlled for egg weight decreases with temperature as the only explanatory variable. When other variables are controlled for, the only (marginally nonsignificant) relationship with temperature that remains is a negative relationship between albumen and temperature. (That is also true when egg weight [both linear and quadratic terms], but not date, is controlled for.) Both albumen and shell weight (whether controlled for egg weight or not) increase with laying date, mirroring the relationship for egg weight. When other variables are controlled for, the relationship between shell weight controlled for egg weight and laying date disappears, suggesting that shell weight increases within clutches as the season progresses, but only by an amount expected on the basis of the increase in egg weight. Yolk weight increases and yolk weight controlled for egg weight decreases in relation to laying date as the only explanatory variable, and both decrease when clutch differences are controlled for. The relationship is significant for neither variable when other explanatory variables are controlled for, so it is not possible to say whether yolk size remains constant or whether it increases seasonally as expected on the basis of the seasonal increase in whole egg weight. Most of the component weights exhibit curvilinear relationships with laying sequence (see Table 1).

As was the case for egg weight, analyses of weights of components of individual eggs controlling for clutch consider only within clutch variation, so between clutch variation was investigated by analyzing clutch means. Mean yolk weights did not vary with laying date or temperature when those explanatory variables were considered alone or in addition to the other variable (all $P \geq 0.2$ ). That was also true for mean yolk weight controlled for whole egg weight (all $P>0.4$ ), so it is not possible to say whether average yolk weight remains constant or increases as expected on the basis of the seasonal increase in average egg weight. Mean albumen weight increases with either laying date or temperature $(P<0.05)$, but neither variable explains a significant additional amount of variance when the other variable is controlled for $(P>0.2)$. Mean shell weight shows the same pattern as mean albumen weight (except that the relationship with temperature alone is mar- 


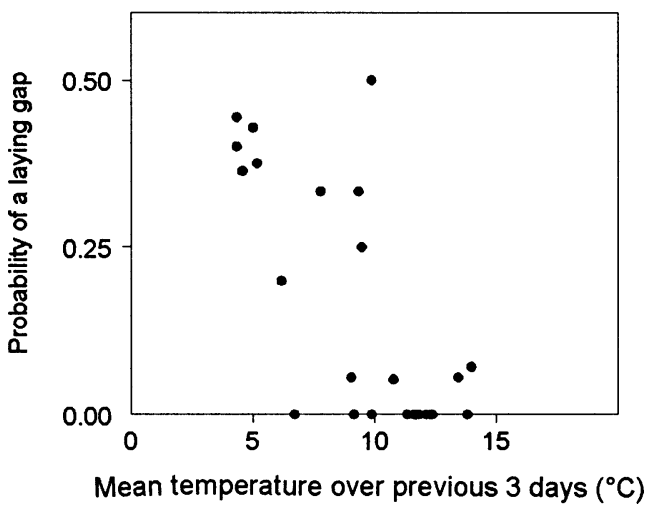

FIG. 2. The occurrence of laying gaps in Great Tits in relation to the mean temperature in the previous three days. Each point represents one day.

ginally nonsignificant; $P=0.072$ ). When those shell weight relationships are controlled for whole egg weight, none of the relationships remain significant $(P>0.2)$. Thus, average shell weight increases with either laying date or temperature, but only to the extent expected on the basis of increases in average whole egg weight with those variables.

Laying gaps in relation to clutch, laying order, laying date, and temperature.-Because nests were visited every day during laying, the days on which laying gaps occurred are known. The effect of clutch, laying sequence, laying date, and temperature on the occurrence of laying gaps was investigated using a series of generalized linear models similar to those in Table 1 with the occurrence of a gap (laid or did not lay) as response variable, and with binomial errors and a logit link. The days on which the first and last egg of the clutch were laid were excluded from the analysis because by definition laying gaps could not occur on those days. A quadratic egg number term was never significant, so only a linear term was included in the analyses. All four explanatory variables (clutch, egg number, date, and temperature) were then significant in all models. In the full model, the probability of a laying gap occurring varied between clutches (change in deviance $=71.38, \mathrm{df}=37, P<0.001)$, increased with position in the laying sequence (change in deviance $=5.029$, df $=1, P<0.05)$, and decreased with both date (change in deviance $=$ 10.71, $\mathrm{df}=1, P<0.001$ ) and mean temperature over the preceding three days (change in deviance $=10.98,1 \mathrm{df}=1, P<0.001 ;$ Fig. 2 ).

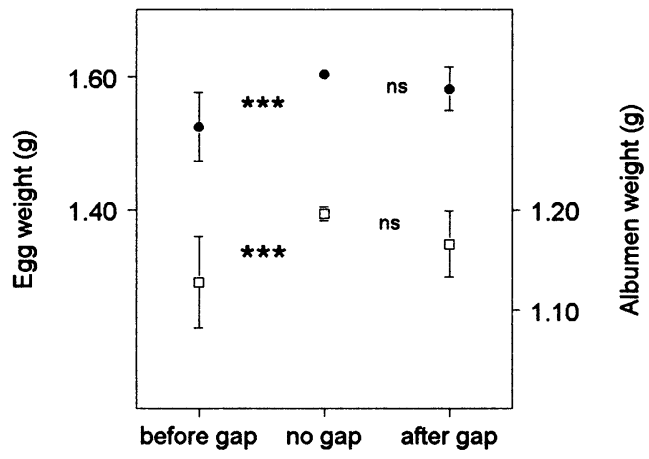

FIG. 3. Whole egg weight (filled circles) and albumen weight (open squares) of Great Tit eggs immediately preceding or following laying gaps in comparison with other eggs. In the statistical comparisons, first eggs and last eggs were excluded in the analyses of eggs laid after a gap and eggs laid before a gap, respectively. Actual differences between the "no gap" group for the two cases are sufficiently small to be visually indistinguishable on this figure, so only one "no gap" group has been plotted. Vertical bars represent SE. ${ }^{* * *} P<0.001$; NS $P>0.05$.

Whole egg, yolk, albumen, and shell weights in relation to the occurrence of laying gaps.-The previous analysis suggests that temperature has an influence on the occurrence of laying gaps. To investigate that further, weights of the whole egg and egg components immediately preceding or following laying gaps were compared to those of other eggs (excluding last eggs in the analysis of eggs preceding gaps, and excluding first eggs in the analysis of eggs following gaps) in two series of general linear models (for eggs before and eggs after gaps) similar to those in Table 1. Whole egg weight and albumen weight tended to be lower in eggs preceding gaps (Fig. 3; $P<0.06$ in both cases), and that difference was significant after controlling for clutch $(P<0.001$ in both cases), or clutch, laying sequence, laying date, and temperature (whole egg: $P=0.011$; albumen: $P=$ 0.004). Shell weight was greater in eggs before gaps, but only after controlling for clutch, laying sequence, laying date, and temperature $(P$ $<0.001$, whether or not controlled for whole egg weight). Shells also tended to be heavier after gaps, after controlling for other variables, but that was only significant when whole egg weight was controlled for $(P=0.025)$. Yolk weight did not differ between eggs before or after gaps and other eggs. 


\section{DisCUSSION}

The main aim of the analyses presented here was to determine whether the within-clutch variation in the weight of the whole egg or of egg components was related to temperature in the days preceding laying, after controlling for other variables. In both 1978 and 1979 that was the case, although slopes of relationships in the two years differed significantly (cf. van Noordwijk 1984, who showed that egg weight increased with temperature in 1979, but did not control for other variables, and did not test for a relationship with temperature in 1978). In contrast, in 1999 there was no evidence for a within-clutch relationship with temperature after controlling for other variables. There was also little evidence for any within-clutch relationship between weights of egg components and temperature after controlling for other variables (except a marginally nonsignificant decrease in albumen weight). However, because there was no overall relationship, the data presented here are not revealing as to relative contributions of different egg components when an overall relationship does occur. Analyses of within-clutch variation in the weights of whole eggs and egg components are likely to be particularly informative when investigating the effects of environmental variables such as temperature, because they exclude genetic variation which is a major component of variation between clutches (van Noordwijk 1984). Nevertheless, we also examined betweenclutch variation in weights of whole eggs and egg components. Those analyses showed that average whole egg, albumen weights, and shell weights increased, and shell weights corrected for whole egg weight and yolk weights (whether or not corrected for whole egg weight) did not vary, with either temperature or laying date, but in no case was it possible to separate the effects of laying date and temperature statistically.

One obvious question is why the withinclutch relationship between egg weight and temperature varies between years. Interactions between environmental variables are frequent in their effect on egg weight. For example, Nager and Zandt (1994) found a significant interaction between temperature and food abundance on the mean egg weight of Great Tit clutches. The differences between years found in the present study might reflect such an interaction. Alternatively, an interaction may be created if the relationship with temperature is nonlinear and females experience different ranges of temperature in different years. Van Noordwijk (1984) suggested that the relationship between egg weight and temperature might exhibit a threshold, but we were unable to confirm that for within-clutch variation in egg weight. Lastly, in years when variation in temperature experienced by individual laying females is low, it will be relatively difficult to detect any within-clutch relationship between egg weight and temperature. However, that should not create an interaction between years and temperature in their effects on egg weight.

The data that we collected can also be used to investigate whether there is a relationship between whole egg and egg component weights and date, independent of temperature. In 1999, the analysis of within-clutch variation revealed that egg weight increased with laying date, and that was accompanied by an increase in albumen and shell weight (although in the latter only to the extent expected on the basis of the increase in egg weight). Yolk weight did not increase significantly with laying date, but neither did yolk weight controlled for egg weight decrease significantly, so no conclusion can be reached as to whether yolk weight increases seasonally in parallel with egg weight. Egg weight also increased seasonally in 1978. Analysis of clutch means revealed the same pattern of relationships between whole egg and egg component weights as the analyses of within-clutch variation, although (as mentioned before) it is not possible to statistically separate effects of laying date and temperature. A seasonal increase in the average egg weight of clutches has previously been reported for Great Tits (Perrins 1970), and because of the much larger sample size ( $n=4,752$ clutches), it was possible to show that the relationship remained significant after controlling for temperature (Perrins 1996). Seasonal changes in egg weight presumably reflect seasonal changes in costs and benefits of producing large eggs (Birkhead and Nettleship 1982). Large eggs may be more difficult to produce early in the season, either because laying females face larger energetic demands of thermoregulation, or because food is less abundant (Perrins 1970). Alternatively, large eggs may be of greater ben- 
efit later in the year. For example, young hatching late in the season are raised after the peak in food availability and after fledging must compete with a larger number of other fledglings, and may therefore benefit from hatching with larger reserves (Murton and Westwood 1977, Verboven and Visser 1998, Both et al. 1999). If more costly thermoregulation early in the season is the only explanation, the relationship between egg size and date should disappear after controlling for temperature, as it does in Eurasian Blackbirds (Magrarth 1992). In Great Tits (Perrins 1996, this study) the relationship persists, implying that increased food availability for laying or an increased benefit of large eggs late in the season is the explanation for the seasonal trend. In terms of egg components, shell weight increases seasonally as expected on the basis of the increase in whole egg weight. There is insufficient statistical power to determine whether that is also the case for yolk weight, or whether yolk size relative to egg size decreases seasonally. If the latter were the case, it would imply that there was selection for increased albumen size later in the season, perhaps through some involvement in the water balance of the developing embryo (Simkiss 1980). If changes in the whole egg and egg component weights are indeed anticipatory responses to seasonally changing conditions, it is surprising that relationships are found within clutches, because the onset of incubation and hatching of Great Tit first clutches are synchronous, and all eggs from a clutch should encounter the same predicted conditions. One possible explanation is that a seasonal change in clutch mean values is achieved by a mechanism that adjusts the size and composition of each egg according to its individual laying date and that within-clutch variation is an unselected consequence of that.

Whole egg weight and the weight of egg components varied significantly through the laying sequence. For whole egg, yolk and albumen weights, the relationship tended to be U-shaped, but this was inverted for shell weights. This was not simply a consequence of a limitation in shell-producing capacity being exacerbated for the larger eggs early and late in the laying sequence, because the absolute shell weight, and not just shell weight controlled for egg weight, showed this pattern. A variety of relationships have been previously reported from different species between egg weight and laying sequence (see Aparicio 1999 for a brief review). In Great Tits a previous study found no consistent relationship (Ojanen et al. 1981). Variation in egg size through the laying sequence has been interpreted as a means of compensating for (Howe 1976, 1978) or emphasizing (Slagsvold et al. 1984) the effects of hatching asynchrony, or as adaptive variation in relation to the reproductive value of eggs (Williams et al. 1993). Alternatively, it might be produced as a result of an imperfect physiological control mechanism that is not selected against because the costs of perfect control producing eggs of uniform size and composition within a clutch would outweigh any benefits. The reasons for the laying sequence patterns that we found in Great Tits are unknown.

Although the relationships between whole egg and egg component weights and other variables tend to be similar within and between clutches, that is not the case for allometric relationships. Yolk weights increase in direct proportion with egg weight within clutches, but less than in proportion with egg weight across clutches, whereas the reverse is true for shell weight. Within-clutch comparisons reveal changes in the proportion of yolk and shell when individual females lay eggs of different sizes, whereas the between-female comparisons reveal differences in the proportion of yolk and shell when different females lay eggs of different average size. The allometric constants suggest that increasing yolk size is more difficult or less necessary for females that lay larger eggs than for individual females laying an egg that is larger compared with the rest of the clutch, and that the reverse is true for shell weight. However, why that might be so is unclear. One explanation for yolk weight is that, whereas the clutch means for whole egg weight increase seasonally, those for yolk weight do not. However, the allometric constant between clutches is essentially the same whether laying date is controlled for $(0.645 \pm 0.155$ [SE] $)$ or not $(0.603 \pm 0.180)$.

In contrast to egg weights, there was a clear relationship between the occurrence of laying gaps and low temperatures (as also reported by Schmidt and Hamann 1983). The same pattern has been found in Blue Tits, where experimentally reduced temperatures increased the probability of laying gaps without affecting egg 
weight (Yom-Tov and Wright 1993) (and supplementary feeding reduced the probability of laying gaps; Nilsson and Svensson 1993). One possible explanation for that pattern is that females were already producing eggs of close to the minimum size and could only reduce their investment in egg production further by temporarily suspending laying. That is opposite to the conclusions of Nager and van Noordwijk (1992), in relation to the onset of laying, that females buffered short-term energetic stress by reducing egg size rather than egg production. It seems that both patterns-maintaining egg size or maintaining egg production-may occur within one species, depending on circumstances. A number of other relationships also suggest that laying gaps are associated with nutritional stress: first, eggs before laying gaps were lighter, apparently because they contained less albumen. In the only other study of egg composition in relation to laying gaps (Kennamer et al. 1997), the last egg in Wood Duck (Aix sponsa) clutches showed a nonsignificant tendency to contain more yolk and lipid when preceded by a laying gap. In Blue Tits, eggs laid before gaps were lighter and eggs laid after gaps were heavier than corresponding eggs in clutches without gaps (Nilsson and Svensson 1993). Second, laying gaps were more frequent later in the laying sequence, a pattern also found in Wood Ducks (Kennamer et al. 1997), but opposite to that previously reported for a range of hole-nesting species (including Great Tits [Schmidt and Hamann 1983] and Blue Tits [Nilsson and Svensson 1993]), although none of those other studies controlled for temperature. Laying gaps may be more likely to occur later in the laying sequence because females have depleted some kind of nutrient reserve (Jones and Ward 1976, Houston et al. 1983), or because females are less able to predict conditions later in the laying sequence at the time that they begin laying (Magrath 1992). Third, laying gaps are less frequent later in the season (after controlling for temperature), perhaps because food is more abundant then. The fact that laying gaps are so clearly related with variables that imply nutritional stress weakens the case that they may function as a mechanism that allows females to control the sex ratio of their broods (Emlen 1997).

In conclusion, the lack of a relationship between egg weight and temperature in 1999 lim- ited the extent to which data presented here throw light on the effects of temperature on individual egg components. However, our results do show an effect of temperature on the occurrence of laying gaps, and confirm an effect of temperature on egg weight in two other years, even after controlling for other variables. Moreover, our results highlight two common features of egg variability that emphasize the need for further studies of egg size and composition. The first is the commonness of interactions between different factors: the relationships of egg weight with temperature, laying date, and laying sequence all differed significantly between 1978 and 1979. The second is that although there is frequently an overall relationship between the weights of individual egg components and whole egg size (Williams 1994), those relationships may vary with factors influencing egg weight: allometric relationships for yolk and shell weight appear to be different within and between clutches, and the seasonal increase in egg weight may not be accompanied by an increase in yolk weight. More data are needed to disentangle the relationships between egg components and environmental variables.

\section{ACKNOWLEDGMENTS}

We are grateful to Het Geldersch Landschap and Het Nationale Park de Hoge Veluwe for permission to carry out work at the study sites, P. de Goede and C. Kerlen-Mateman for help with field and laboratory work, A. van Noordwijk and J. Visser for help with extracting the 1978 and 1979 data from the long-term database, and Marcel Visser for comments on an earlier draft of this paper.

\section{Literature Cited}

ANKNEY, C. D., AND S. L. JoHNSON. 1985. Variation in weight and composition of Brown-headed Cowbird eggs. Condor 87:296-299.

APARICIO, J. M. 1999. Intraclutch egg-size variation in the Eurasian Kestrel: Advantages and disadvantages of hatching from large eggs. Auk 116: 825-830.

ArCese, P., AND J. N. M. SMITH. 1988. Effects of population density and supplemental food on reproduction in Song Sparrows. Journal of Animal Ecology 57:119-136.

Avery, M. I., AND J. R. KRebs. 1984. Temperature and foraging success of Great Tits Parus major hunting for spiders. Ibis 126:33-38. 
BirkheAd, T. R., AND D. N. NetTleship. 1982. The adaptive significance of egg size and laying date in Thick-billed Murres Uria lomvia. Ecology 63: 300-306.

Both, C., M. E. Visser, And N. Verboven. 1999. Density dependent recruitment rates in Great Tits: The importance of being heavier. Proceedings of the Royal Society of London, Series B 266:465469.

Boutin, S. 1990. Food supplementation experiments with terrestrial vertebrates: Patterns, problems and the future. Canadian Journal of Zoology 68 : 203-220.

EMLEN, S. T. 1997. When mothers prefer daughters over sons. Trends in Ecology and Evolution 12: 291-292.

HAFTORN, S. 1986. Clutch size, intraclutch eggsize variation, and breeding strategy in the Goldcrest Regulus regulus. Journal für Ornithologie 127: 291-301.

Houston, D. C., P. J. Jones, And R. M. Sibley. 1983. The effect of female body condition on egg laying in Lesser Black-backed Gull Larus fuscus. Journal of Zoology (London) 200:509-520.

Howe, H. F. 1976. Egg size, hatching asynchrony, sex, and brood reduction in the Common Grackle. Ecology 57:1195-1207.

Howe, H. F. 1978. Initial investment, clutch size, and brood reduction in the Common Grackle (Quiscalus quiscula L.). Ecology 59:1109-1122.

JÄrvinen, A. 1991. Proximate factors affecting egg volume in sub-Arctic hole-nesting passerines. Ornis Fennica 68:99-104.

JÄrVINEN, A., AND M. PRYL. 1989. Egg dimensions of the Great Tit Parus major in southern Finland. Ornis Fennica 66:69-74.

JÄRVINEN, A., AND J. YlimAUnU. 1986. Intraclutch egg-size variation in birds: Physiological responses of individuals to fluctuations in environmental conditions. Auk 103:235-237.

JONES, P. J., AND P. WARD. 1976. The level of reserve protein as the proximate factor controlling the timing of breeding and clutch-size in the Redbilled Quelea, Quelea quelea. Ibis 118:547-574.

Kennamer, R. A., S. K. Alsum, And S. V. Colwell. 1997. Composition of Wood Duck eggs in relation to egg size, laying sequence, and skipped days of laying. Auk 114:479-487.

MAGRATH, R. D. 1992. Seasonal changes in egg-mass within and among clutches of birds: General explanations and a field study of the Blackbird Turdus merula. Ibis 134:171-179.

MARTIN, T. E. 1987. Food as a limit on breeding birds: A life history perspective. Annual Review of Ecology and Systematics 18:453-487.

MeIJeR, T., AND R. DRENT. 1999. Re-examination of the capital and income dichotomy in breeding birds. Ibis 141:399-414.
MumA, K. E., AND C. D. ANKNEY. 1987. Variation in weight and composition of Red-winged Blackbird eggs. Canadian Journal of Zoology 65:605607.

Murton, R. K., And N. J. Westwood. 1977. Avian Breeding Cycles. Clarendon Press, Oxford, United Kingdom.

NAger, R. G., AND A. J. VAn NoORdwiJk. 1992. Energetic limitation in the egg-laying period of Great Tits. Proceedings of the Royal Society of London, Series B 249:259-263.

NAGer, R. G., AND H. S. ZANDT. 1994. Variation in egg size in Great Tits. Ardea 82:315-328.

Nilsson, J.-Å., AND E. Svensson. 1993. The frequency and timing of laying gaps. Ornis Scandinavica 24:122-126.

OJANEN, M. 1983a. Effects of laying sequence and ambient temperature on the composition of eggs of the Great Tit Parus major and the Pied Flycatcher Ficedula hypoleuca. Annals Zoologica Fennici 20:65-71.

OJANEN, M. 1983b. Composition of the eggs of the Great Tit (Parus major) and the Pied Flycatcher (Ficedula hypoleuca). Annals Zoologica Fennici 20:57-63.

OJANEN, M., M. ORELl, AND R. VÄISÄNEN. 1981. Egg size variation within passerine clutches: Effects of ambient temperature and laying sequence. Ornis Fennica 58:93-108.

Perrins, C. M. 1965. Population fluctuations and clutch size in the Great Tit, Parus major. Journal of Animal Ecology 34:601-647.

PERrins, C. M. 1970. The timing of birds' breeding seasons. Ibis 112:242-255.

Perrins, C. M. 1991. Tits and their caterpillar food supply. Ibis 133:49-54.

PERrins, C. M. 1996. Eggs, egg formation and the timing of breeding. Ibis 138:2-15.

SCHMIDT, K.-H., AND H.-J. HAMANN. 1983. Unterbrechung der Legefolge bei Höhlenbrütern. Journal für Ornithologie 124:163-176.

SIMKISS, K. 1980. Water and ionic fluxes inside the egg. American Zoologist 20:385-393.

Slagsvold, T., J. SAndviK, G. Rofstad, O. LorenTSEN, AND M. HusBy. 1984. On the adaptive value of intra-clutch egg-size variation in birds. Auk 101:685-697.

SOKAL, R. R., AND F. J. RoHLF. 1995. Biometry, 3rd ed. W. H. Freeman and Co., New York.

Stevenson, I. R., AND D. M. BRyAnt. 2000. Climate change and constraints on breeding. Nature 406: 366-367.

VAN NoORDWIJK, A. J. 1984. Quantitative genetics in natural populations of birds illustrated with examples from the Great Tit (Parus major). Pages 67-79 in Population Biology and Evolution (K. Wöhrmann and V. Loeschke, Eds.). Springer, Berlin. 
VAN NoOrdwiJK, A. J., R. H. MCCleEry, AND C. M. PERRINS. 1995. Selection for the timing of Great Tit breeding in relation to caterpillar growth and temperature. Journal of Animal Ecology 64:451458.

VERBOVEn, N., AND M. E. VISSER. 1998. Seasonal variation in local recruitment of Great Tits: The importance of being early. Oikos 81:511-524.

Williams, T. D. 1994. Intraspecific variation in egg size and egg composition in birds: Effects on off- spring fitness. Biological Reviews of the Cambridge Philosophical Society 68:35-59.

Williams, T. D., D. B. LANK, AND F. COOKE. 1993. Is intraclutch egg-size varaition adaptive in the Lesser Snow Goose? Oikos 67:250-256.

YOM-TOV, Y., AND J. WRIGHT. 1993. Effect of heating nest boxes on egg laying in the Blue Tit (Parus caeruleus). Auk 110:95-99.

Associate Editor: C. Blem 